\title{
Formulação de Estratégias no Turismo: um estudo em órgãos municipais do Estado de São Paulo ${ }^{1}$
}

Strategies Formulation in Tourism: a study in municipal state agencies in the State of São Paulo

Benny Kramer Costa ${ }^{2}$

João Maurício Gama Boaventura ${ }^{3}$

Leilianne Michelle Trindade da Silva Barreto ${ }^{4}$

\section{Resumo}

O objetivo desta pesquisa é investigar a formulação de estratégias em órgãos públicos municipais de turismo do Estado de São Paulo. Para este fim realizou-se um estudo de casos múltiplos em seis municípios: Santos, Guarujá, Praia Grande, São Caetano do Sul, Rio Grande da Serra e Guarulhos. Os dados foram coletados através de entrevistas semiestruturadas. Constatou-se que estes órgãos municipais desenvolvem um encaminhamento lógico na formulação de estratégias, os quais apresentam em seus estágios iniciais características de informalidade, e na evolução deste processo contemplam-se necessidades e desejos dos consumidores e de outros stakeholders. Todo o processo de formulação de estratégias recebe influência de diversos stakeholders. As principais dificuldades encontradas no processo de formulação estratégica foram: falta de mobilização coletiva, conflitos de interesses e carência de recursos.

Palavras-chave: formulação de estratégias; estratégia no turismo; municípios turísticos.

\begin{abstract}
The goal of this study is to investigate the strategy formulation in Municipal Tourist Agencies, specifically in the State of São Paulo. This is a qualitative research using multi-cases. The object of study was composed by the municipalities tourist agencies of Santos, Guarujá, Praia Grande, São Caetano do Sul, Rio Grande da Serra and Guarulhos. The data collection was provided by semi-structured interviews. The founding showed that agencies develop a logic process of strategy formulation, with informal characteristics in early stages, and it seeks looking to attend the interest of consumers and other stakeholders. The whole process of strategy formulation is influenced by several stakeholders. The difficulties observed in the process were the lack of collective mobilization, conflicts of interests, and a lack of resources. Keywords: strategies formulation; strategy in tourism; tourist destinations.

\footnotetext{
${ }^{1}$ Uma versão preliminar deste trabalho foi apresentada no V Seminário da Associação Nacional de Pesquisa e Pós-Graduação em Turismo, realizado nos dias 25 e 26 de agosto de 2008, em Belo Horizonte/MG.

${ }^{2}$ Professor do Programa de Mestrado e Doutorado em Administração da Universidade Nove de Julho (PMDAUNINOVE) e do Departamento de Relações Públicas, Propaganda e Turismo da Universidade de São Paulo (USP). E-mail: bennycosta@yahoo.com.br

${ }^{3}$ Doutor em Administração de Empresas pela Universidade de São Paulo, Professor e Coordenador do Programa de Mestrado Profissional em Administração da Fundação Instituto de Administração - FIA. Professor da FEAUSP, do Programa de Mestrado em Administração da Universidade Paulista - UNIP e da Fundação Escola Comércio Álvares - FECAP. E-mail: jm@boaventura.adm.br

${ }^{4}$ Doutoranda em Administração pela Universidade de São Paulo - USP; Mestre em Administração e Bacharel em Turismo pela Universidade Federal do Rio Grande do Norte - UFRN. E-mail: leilianne_mts@hotmail.com
} 


\section{Introdução}

O turismo é um setor de reconhecida importância e se configura como um dos segmentos de mais rápido crescimento na economia mundial. De acordo com a OMT (2007), houve 845,5 milhões de chegadas de turistas ao redor do mundo em 2006. A Europa fica com a maior parcela, recebendo 461 milhões, ao passo que a América Latina recebeu 18,7 e o Brasil 5 milhões de turistas. Ao fazer uma análise histórica do fluxo turístico e da receita gerada no país, observa-se que esses valores são sempre crescentes, o que gera uma perspectiva de que o setor continue se desenvolvendo e gerando benefícios por muitos anos. Em 2006, a receita cambial turística movimentou 4,3 bilhões de dólares. No mesmo ano, só o Estado de São Paulo, principal portão de entrada do Brasil, recebeu 2,3 milhões de turistas (EMBRATUR, 2007).

No Brasil, têm-se realizado diversos estudos relacionados à atividade turística, porém os esses trabalhos obedecem a fins e interesses bastante específicos, seja por parte de seus compradores (que encomendam) ou de seus fornecedores (que realizam a pesquisa). Ambas as partes, atuando em função de seus interesses específicos, levam o total de pesquisas efetuadas a uma desconexão e falta de integração entre si, perdendo, portanto, o efeito multiplicador e a sinergia.

Para sustentar o crescimento dessa atividade é essencial que as organizações ligadas ao turismo utilizem os preceitos da estratégia. Entretanto, pouco tem sido estudado e produzido em relação à formulação estratégica relacionadas ao turismo em municípios. Assim, considera-se importante aumentar a consciência em relação ao progresso da estratégia no turismo e prover uma base inicial para a formulação de um pensamento, bem como a realização de um debate contínuo neste importante tema, em níveis local, nacional e internacional. Cabe ainda mencionar a relevância que o setor público assume no processo de formulação de estratégias para destinos turísticos, por meio da sua capacidade de envolver os diversos stakeholders e de nortear as ações a serem tomadas para a organização da atividade.

Nesse contexto, o presente artigo se propõe a analisar a formulação de estratégias em órgãos públicos municipais de turismo do Estado de São Paulo. Para alcançar o objetivo proposto, foi desenvolvido um estudo exploratório, com a intenção de conhecer e delinear este processo. Quanto à abordagem metodológica, este estudo fez a opção pela pesquisa qualitativa, com o intuito de obter maior profundidade e riqueza de conteúdos. 
Em relação à extensão do campo de estudo, optou-se pela pesquisa classificada como monográfica e de profundidade, a qual permite o exame do maior número possível de variáveis que interfiram no tema (Abramo, 1979, p. 39). Em relação ao formato, escolheu-se o estudo de casos múltiplos em função do direcionamento da pesquisa para um setor específico da atividade econômica - o turismo - no qual a ocorrência do fenômeno em questão é considerada importante e potencialmente genérica.

A amostragem correspondeu ao tipo não-probabilístico, em que se buscou profundidade de conhecimento em seis órgãos municipais de turismo, em Santos, Guarujá, Praia Grande, São Caetano do Sul, Rio Grande da Serra e Guarulhos.

No que tange ao instrumento de coleta de dados, a opção recaiu sobre a observação direta, por meio do uso de entrevista semi-estruturada. Também, utilizou-se a observação indireta, por meio de consulta bibliográfica e documental. Os dados foram coletados entre outubro de 2006 e janeiro de 2007.

Em relação à análise dos dados, com base nas recomendações de Yin (1994), estabeleceu-se uma estratégia analítica baseada em proposições teóricas, ou seja, o estudo tomou como base proposições que refletem revisões feitas na literatura e as novas interpretações que possam surgir. Operacionalmente, as análises foram realizadas a partir da construção de uma explanação sobre os casos, visando verificar as semelhanças e os contrastes existentes em relação aos diversos atributos de formulação estratégica investigados.

Diante do exposto, nos tópicos seguintes inicialmente são apresentados os subsídios teóricos sobre estratégia em municípios turísticos. Na seqüência, tem-se a discussão dos resultados e as considerações finais. A análise dos resultados é feita por município e contempla os seguintes aspectos: ações tomadas, surgimento de estratégias, influências recebidas, dificuldades encontradas, forma de elaboração e nível de complexidade.

\section{Estratégia: Conceitos e Formulação}

Estratégia é um termo milenar que foi utilizado inicialmente na área militar. Atualmente, diversas outras áreas têm aplicado a definição de estratégia em suas atividades, tanto na perspectiva privada como na pública. As definições do termo também são bastante variadas. 
Na tentativa de agrupar os conceitos, Mintzberg (1990) propõe três grandes tipos de escolas de formulação de estratégias. O primeiro seria o das escolas prescritivas, as quais enfatizam o modo como as estratégias devem ser formuladas. O segundo grupo é denominado de escolas descritivas, que se preocupam em descrever como as estratégias são realmente formuladas. $\mathrm{O}$ último grupo na verdade é composto pela escola de configuração, a qual visualiza como essência do processo a transformação e as mudanças estratégicas.

Analisando-se os diversos autores de estratégia, percebe-se que há um grupo de estudiosos que procura relacionar estratégias com objetivos ou metas, como em uma relação causaefeito, ou seja, como se a estratégia estivesse imbuída de empregar os meios existentes para atingir determinados objetivos. Nesta linha de pensamento, Chandler (1962, p. 13) define estratégia como a determinação das metas e de objetivos básicos de uma empresa para o longo prazo, assim como a adoção de cursos de ação e a alocação dos recursos necessários para atingir essas metas. Do mesmo modo, Drucker (1977, p. 584) caracteriza a estratégia como a abordagem básica adotada por uma empresa para atingir seus objetivos.

Christensen et al. (1978, p. 125) também têm uma visão semelhante de estratégia e a definem como um padrão de decisões em uma empresa que: 1- define e revela objetivos e metas, 2produz as principais políticas e planos para se atingir tais objetivos e metas, e 3-define o negócio em que a empresa está ou pretende estar.

Bethlem (2001, p. 40) faz uma associação clara entre objetivos e estratégias, empregando o termo objetivo genéricos, relacionado ao lucro, crescimento, sobrevivência e prestígio, e entende que as estratégias genéricas são decorrentes destes objetivos genéricos.

Lorange e Vancil (1977, p. 12) também entendem que a estratégia visa a atingir objetivos e explicam que a estratégia pode ser dividida em três níveis: 1- corporativa, cujos objetivos são voltados para o interesse dos acionistas, 2- da unidade de negócios, em que os objetivos são definidos pela administração da corporação, e 3- por atividades, cujos objetivos são definidos pela administração da unidade de negócios.

Outro conjunto de definições encontrado na literatura relaciona estratégia a vantagens competitivas. O pressuposto é que a estratégia deve estar orientada para alcançar e manter uma vantagem competitiva. A contemplação da idéia de vantagem competitiva no campo da 
estratégia se deu após a introdução do conceito por Porter (1980), que atraiu posteriormente vários seguidores.

A conceituação de estratégia pela vantagem competitiva fica explícita para Henderson (1989 apud Montgomery; Porter, 1998, p. 5), que a entende como a busca deliberada de um plano de ação para desenvolver e ajustar a vantagem competitiva de uma empresa. Hax e Majluf (1991, p. 6) também adotam esta premissa e concluem que a essência da estratégia é propor como alcançar e manter a vantagem competitiva.

Outro seguidor de Porter é Andrews (1987, p. 14), que, apesar de entender a estratégia como um meio de atingir objetivos, adiciona ao seu conceito a idéia de se desenvolver a vantagem competitiva pela competência essencial, afirmando que a estratégia deve enfatizar uma forma de converter a competência distintiva (essencial) em vantagem competitiva.

A questão das competências essenciais citadas acima norteou as idéias de outro grupo de pensadores de estratégia, os quais compartilham a visão de que eventuais vantagens competitivas, ou ainda vantagens na interação com oponentes, serão decorrentes das competências essenciais da organização. Em suma, este ficou sendo o ponto importante da estratégia.

Werther e Kerr (1995) enfatizam os aspectos relativos às competências essenciais, atestando a relação entre competências e competitividade através de estudos de casos onde a ausência de novas competências impediu a manutenção da liderança de mercado de algumas organizações.

Hamel e Prahalad (1995, p. 26), além de considerarem tais aspectos da estratégia, salientam a importância de se pensar no futuro e citam que é preciso uma arquitetura estratégica que elabore a planta para a construção de competências necessárias para dominar os mercados futuros.

Ainda analisando os conceitos de estratégia desenvolvidos ao longo do tempo, é possível visualizar a idéia de inter-relação entre estratégia e a interação com os competidores como um ponto comum entre determinado grupo de autores. De certa forma, estes pensadores priorizam a questão das ações e reações dos competidores, ou seja, acreditam que uma estratégia não possa existir sem considerar como, de forma mútua, a empresa afeta seus oponentes e é por eles afetada.

Newman (1950, p. 110), por exemplo, relaciona estratégia com previsão de reações, ao definila como ajuste de um plano para antecipar as reações daqueles que serão afetados pelo plano. 
Nesse sentido, Dixit e Nalebuff (1991) entendem ser o pensamento estratégico a arte de superar um adversário, sabendo que ele está tentando fazer a mesma coisa em relação a você.

Para Schelling (1960, p. 3), o termo estratégia pretende focalizar a interdependência das decisões dos adversários e de suas expectativas a respeito do comportamento de uns e de outros. Zaccarelli (2000, p. 73) também compartilha essa visão definindo estratégia como um guia para decisões sobre interações com oponentes, de reações imprevisíveis, compreendendo duas partes: ações e reações envolvendo aspectos do negócio e preparação para obter vantagens nas interações.

\section{Estratégia em Municípios Turísticos}

Todos os pontos essenciais do conceito de estratégia discutidos até aqui são de grande importância para as destinações turísticas, as quais competem de forma cada vez mais agressiva na atual economia globalizada. Assim, as estratégias são vistas como uma ferramenta para adquirir vantagem competitiva e alcançar o sucesso, através de seu correto planejamento e implementação (Claver-Cortés et al., 2006).

Especificamente no campo do turismo, estudos relacionados a estratégia tem sido desenvolvidos por alguns autores, como Getz (1983), Fletcher e Cooper (1996), Costa (1999), Ritchie (2004), Stokes (2008), entre outros.

Getz (1983) elenca uma série de etapas que compõem o processo de planejamento estratégico no turismo: descrição e modelagem do sistema turístico e de seu ambiente; previsão e escolha de alternativas futuras; avaliação do desenvolvimento planejado; determinação das metas e objetivos que serão priorizados; seleção das estratégias preferidas para o alcance dos objetivos; início do desenvolvimento incremental; revisão e avaliação do planejamento; e novo processo de tomada de decisões.

Ritchie (2004) resume essas etapas em quatro fases, a saber: análise estratégica, onde se examinam os ambientes macro e micro; escolha estratégica, etapa em que se definem as direções a serem seguidas e as estratégias específicas a serem desenvolvidas; implementação da estratégia, em que se desenvolvem os recursos e se colocam as estratégias em prática; e 
feedback estratégico, momento em que se avaliam as estratégias em busca do aprimoramento e melhoria contínua.

Costa (1999) desenvolveu um método de análise estratégica voltado para o setor turístico. Em um primeiro momento, ele sugere a análise interna das organizações com ênfase nos recursos e ativos, que podem perfeitamente serem utilizadas para o monitoramento de municípios turísticos. A segunda etapa seria a análise macroambiental, que envolve os ambientes econômico, político, social, cultural, educacional, religioso, tecnológico, infraestrutural, turístico, geográfico, ecológico, internacional, financeiro, eventos e jurídico-legal. Em seguida, se dá a análise das fontes supridoras de recursos. Contempla-se, também, nesse modelo, a análise dos mercados turísticos atual e futuro.

Vários autores destacam que, para sobreviverem no mercado, que é caracterizado por um ambiente em constante transformação, os municípios turísticos precisam compreender profundamente as forças que atuam sobre o seu sistema, interpretando-as como oportunidades ou ameaças, investigando os fatores críticos e visando à otimização dos aspectos positivos e a minimização dos efeitos negativos do desenvolvimento do turismo, para embasar a formulação de estratégias e fazer as escolhas adequadas (Xiang; Formica, 2007; LuqueMartinez et al., 2007; Fletcher; Cooper, 1996).

Reforçando esse aspecto, Castro (2004), por exemplo, destaca o planejamento estratégico desenvolvido pelos órgãos públicos responsáveis pela atividade turística no Estado da Bahia como um dos fatores preponderantes para o alcance do seu respeitável posicionamento no turismo receptivo nacional e internacional.

Para Xiang e Formica (2007), a estratégia é uma importante ferramenta para a adaptação ao ambiente e a redução de incertezas. Os processos de formulação, implementação e avaliação de estratégias deve estar embasado no diagnóstico do ambiente. Por outro lado, os autores enfatizam a dificuldade inerente a esses processos, uma vez que o ambiente é bastante dinâmico e complexo, o que torna penosas a sua análise e interpretação.

Vale ressaltar que muitas vezes os gestores de localidades e comunidades adotam estratégias indiscriminadamente, sem passar por um processo de reflexão cuidadoso em relação às conseqüências de longo de prazo, sendo imediatistas e visando apenas à aceitação popular no curto prazo (Fitzgerald; Leigh, 2002). 
Nesse sentido, o Brasil tem apresentado certa incapacidade de planejamento turístico, em função da falta de competência dos órgãos públicos de gestão do turismo em diversas áreas do país. Como ilustração, o estudo de Delamaro et al. (2007), realizado junto aos municípios do Cone Leste Paulista, mostrou que os órgãos públicos municipais da região não compartilham uma cultura de planejamento, apresentam um descompasso entre o discurso e a prática, possuem deficiência de pessoal e qualificação, não implementam satisfatoriamente as ações planejadas e não envolvem a participação social nos planejamentos.

Por outro lado, a criação do Ministério do Turismo em 2003 demonstra o interesse do poder público em reverter essa situação no Brasil, dedicando atenção especial ao setor, com a disponibilização de estrutura e orçamento próprios, além da autonomia que tal órgão representa.

Para que o planejamento estratégico seja sustentável, Stokes (2008, p. 255) aponta como tendência na formulação de estratégias a transição de um processo caracterizado pela passividade para um caracterizado pelo intervencionismo, através da responsabilidade compartilhada. O autor considera essencial a colaboração e o engajamento dos stakeholders na formulação de estratégias e decisões de turismo.

Essa visão de gestão participativa também é corroborada pela OMT (2003), que afirma que os diversos atores do turismo possuem necessidades e conhecimentos particulares para a tomada de decisões e que a sua participação reduz a chance de resistências. Para Silva e Costenaro (2004, p. 1), "a elaboração conjunta do planejamento estratégico promove alinhamento dos interesses dos participantes à estratégia do desenvolvimento do turismo".

Ainda nessa linha, Sampaio (2003) fala sobre a diferença entre a formulação e a implementação de estratégias e afirma que nem todas as comunidades receptoras de turismo conseguem transformar as ações formuladas em resultados, sejam eles sociais, econômicos ou ambientais. $\mathrm{O}$ autor defende o desenvolvimento de uma gestão estratégica no município, para assegurar que as ações elaboradas sejam efetivamente executadas. Assim, o enfoque participativo dessa gestão se constitui por si só em uma estratégia para facilitar os processos de formulação e implementação, a partir da colaboração de todas as pessoas e entidades que serão afetadas pelas decisões estratégicas do turismo municipal.

Um exemplo positivo é o caso do município de Juiz de Fora/MG, que desenvolveu um Plano Estratégico Setorial de Turismo integrado ao planejamento estratégico geral do município e 
com forte apelo participativo, conseguindo mobilizar mais de 2.000 pessoas na sua elaboração, representadas em diversos grupos de trabalho, além de contar com o apoio de cerca de 60 instituições públicas e privadas. Com essa iniciativa, o município conseguiu o comprometimento contínuo de todos os atores envolvidos, que apoiaram e incorporaram seus objetivos, caminhos e resultados (Forte, 2003).

Entre os aspectos pertinentes ao processo estratégico das organizações citados na literatura, sobressaem: (1) estratégias e ações tomadas (Chandler, 1962); (2) deliberação e emergência de estratégias (Mintzberg; Waters, 1985); (3) influências na formulação de estratégias (Stokes, 2008); (4) dificuldades no processo de formulação de estratégias (Xiang; Formica, 2007) e (5) maneira ou forma de elaboração das estratégias (Fitzgerald; Leigh, 2002). Tais aspectos serão então empregados na observação do objeto de estudo.

\section{Análise dos Resultados}

A análise do processo de formulação de estratégias nos órgãos municipais de turismo do Estado de São Paulo foi realizada em cada um dos casos investigados por meio dos cinco atributos elencados acima na revisão da literatura.

Antes de proceder à análise é importante destacar que todos os municípios pesquisados dispõem de estratégias formuladas em relação ao turismo, a exceção de Rio Grande da Serra, que estava em processo de discussões com os stakeholders locais para a sua elaboração no ano de 2007.

\subsection{Secretaria Municipal de Turismo de Santos}

O município de Santos está localizado no litoral do Estado de São Paulo, a $72 \mathrm{~km}$ da capital. Ele possui $271 \mathrm{~km}^{2}$ de área total e uma população de 417.983 habitantes. Abriga o maior porto da América Latina, que é responsável por movimentar a economia da cidade. Como atividades econômicas, também se destacam o comércio, a pesca e o turismo. Este último se desenvolve principalmente em função dos seus $7 \mathrm{~km}$ de praia e do seu patrimônio histórico. Seu porto recebe um grande fluxo de cruzeiros marítimos e transatlânticos. Além disso, o município conserva uma extensa área de Mata Atlântica, região propícia ao desenvolvimento do ecoturismo. A cidade conta com 18 meios de hospedagem, 87 estabelecimentos de 
alimentação, 07 shoppings, 01 centro de convenções e ainda museus, teatros, centros culturais, cinemas, entre outros.

Analisando-se as estratégias e ações tomadas pela Secretaria Municipal de Turismo de Santos durante o processo de formulação de estratégias, foi possível registrar a adoção das seguintes ações: (a) programa "Santos vai ao interior" - que visa a divulgar a localidade em regiões com potenciais de demanda turística, principalmente, no interior dos estados de São Paulo, Minas Gerais e Paraná e daí aumentar a captação de turistas; (b) "Meca Santos" - Concurso para criação do prato típico da gastronomia santista; (c) atuação do bonde - Que conjuntamente com o acervo arquitetônico tem demandado uma procura significativa da cidade para filmagens provenientes de fora.

Quanto à deliberação e emergência de estratégias, percebeu-se que elas foram inicialmente produzidas a partir de uma equipe interna da prefeitura municipal, que desenhou um pequeno esboço de estratégias para o turismo. A partir daí foram acrescentados e agrupados diversos organismos da sociedade local, com interesses diretos e indiretos no turismo, bem como outros projetos demandados pela comunidade.

Sobre as influências recebidas no processo de formulação de estratégias, foram detectadas as influências de alguns stakeholders significativos, como o COMTUR local (Conselho Municipal de Turismo), o trade turístico, as universidades locais que ensinam o turismo e o Convention \& Visitors Bureau (CVB) do município. Normalmente, em cada programa ou projeto de envergadura coletiva existem parcerias entre a secretaria e os atores listados anteriormente, tais como: participação em feiras e outros eventos em parceria com o CVB, no mínimo para dividir espaço físico; a criação do prato gastronômico, com a Unisantos e o Sindicato dos Hotéis, Bares, Restaurantes e Similares local; o projeto "Santos todos a bordo", com a CVC turismo, empresas de citytour, CONDESP e universidades locais.

Quanto às dificuldades encontradas, observou-se que o seu processo encontra-se em contínua evolução; alguns programas e projetos, em função de sua complexidade, tempo de execução e verbas alocadas, podem repercutir em um maior conjunto de problemas. Os maiores problemas encontrados no início foram a mobilização e a permanente participação dos principais atores locais no processo estratégico; outro ponto difícil foi a comunicação entre os 
participantes e entre os diversos órgãos de governo municipal envolvidos, principalmente, no cumprimento de prazos.

A forma de elaboração de estratégias ocorre inicialmente por meio de idéias e pensamentos prévios; a partir daí se monta um esboço, com a troca de informações e a realização de conversas com os atores locais, no sentido de se conquistar defensores e adeptos da proposta e de se viabilizar parceiros, o que exige uma constante sensibilização e doutrinação dos diversos grupos de interesse. Neste ponto, a mídia impressa e falada ajuda bastante, informando e sensibilizando as entidades e comunidades da localidade.

\subsection{Secretaria Municipal de Turismo do Guarujá}

O município de Guarujá está localizado na Baixada Santista, a $82 \mathrm{~km}$ da capital paulista. Com 304.274 habitantes e $142 \mathrm{~km}^{2}$ de extensão, é a terceira maior ilha do litoral do Estado de São Paulo. O turismo é o principal responsável pela dinâmica econômica da cidade, que é muito procurada por turistas no período de alta temporada. Seu principal atrativo são as belezas naturais, que incluem praias urbanas, praias selvagens e trilhas de ecoturismo. Outras atrações são as construções históricas e a pesca artesanal. Para minimizar a dependência do turismo sazonal, o município vem investindo no turismo de negócios e na prestação de serviços. Outras atividades econômicas envolvem a atividade marítima de lazer, a indústria e a atividade portuária. A cidade possui mais de 9000 leitos e o seu segmento de alimentos e bebidas vem se firmando como importante pólo gastronômico do Estado.

As estratégias e ações relacionadas ao processo de formulação de estratégias na Secretaria Municipal de Turismo do Guarujá centram-se em áreas como segurança, meio ambiente e social, focadas por outros organismos municipais. A segurança está a cargo da secretaria municipal de planejamento, e existe um monitoramento por meio de câmeras, o que tem diminuído em $32 \%$ o número de roubos; particularmente, em períodos de final e começo do ano, implementa-se uma operação verão, envolvendo e integrando as polícias civil, militar e municipal. Quanto ao meio ambiente, no passado houve invasões de áreas de preservação, ampliando-se as favelas no município. Já no campo social, ocorre uma diminuição dos impactos sociais sobre a imagem do município, mediante ações como a criação de programas para congelar o crescimento das favelas locais num primeiro momento e, em seguida, a sua remoção de áreas de risco. 
Em relação à deliberação e emergência das estratégias, elas partiram do plano de governo da gestão municipal atuante na época da pesquisa, com definições prévias dos planejadores. Em seguida, elas foram enriquecidas com outras idéias e conversas, até chegar a discussões coletivas.

No que tange às influências existentes durante a formulação de estratégias, foi detectada a existência de poucas pressões individuais, sendo que a maioria delas se refere a encaminhamentos positivos para o turismo local. Isso se deve à prática de se verificar as necessidades do trade local e pela realização de audiências públicas, gestão mais democrática, orçamento participativo e o uso de pesquisas pontuais para problemas específicos.

As dificuldades observadas durante a formulação de estratégias residem na falta de uma equipe interna na secretaria, em termos de número de pessoas adequadas para a realização das tarefas, embora a qualidade das pessoas existentes seja considerada de bom nível. Também se observou uma dificuldade importante no que se refere à criação de unidade de discurso entre os atores; é comum os envolvidos não acharem um norte no que diz respeito à satisfação de suas necessidades, o que prejudica a priorização e aplicação dos recursos e o foco nos investimentos.

Quanto à maneira ou forma de elaboração das estratégias, a experiência demonstra que a partir das necessidades de promoção do turismo local e captação de eventos para a cidade, se criou um CVB local que mobiliza atualmente mais de 90 pessoas do trade turístico do município, por meio de reuniões, conversas e acordos, e está se traduzindo em uma iniciativa que já está captando eventos para seus equipamentos turísticos; também consta a criação do COMTUR que vem mobilizando lideranças em suas reuniões e decisões sobre o turismo local.

\subsection{Secretaria de Turismo de Praia Grande}

Também na região da Baixada Santista, a 86 km da cidade de São Paulo, o município de Praia Grande possui uma área de $149 \mathrm{~km}^{2}$ e uma população de 249.533 habitantes. A economia da cidade está apoiada no turismo, mas também apresenta como atividades complementares o comércio e serviços. Seus $23 \mathrm{~km}$ de costa fazem da cidade uma das praias mais movimentadas do Brasil, que chega a receber mais de 1 milhão de turistas na alta temporada. 
No contexto das estratégias e ações tomadas pela Secretaria de Turismo de Praia Grande no processo de formulação de estratégias, destacam-se a criação de uma linha turística em parceria com a iniciativa privada, a implantação do posto de informações turísticas, a criação do COMTUR e a revisão do Plano Diretor do Município. No que concerne à deliberação e emergência de estratégias, destaca-se que a localidade é procurada pelas colônias de férias de associações de classe há bastante tempo. Isso estimulou a busca por alternativas que diminuíssem a sazonalidade local, uma vez que a cidade fica repleta de turistas, veranistas e visitantes nas férias de dezembro, janeiro e fevereiro e esvaziada nos demais períodos do ano. Também consta que o surgimento das estratégias é fruto da necessidade de atender às solicitações dos turistas que estavam sendo embasadas no Plano Diretor da Região Metropolitana da Baixada Santista.

As influências no processo de formulação foram provenientes de algumas ações adotadas por outros municípios, que serviram de referência para a localidade; além da mídia em geral quando se refere ao tema do turismo e do próprio turista em suas manifestações em relação ao atendimento no município.

Em relação às dificuldades encontradas, foram percebidas resistências pontuais dos moradores e dos comerciantes locais, muito em função da desinformação reinante entre esses atores e o poder público municipal, o que gerava uma falta de conscientização sobre o tema e sobre a importância do turismo.

Sobre a maneira de elaboração, o processo se deu pela contratação de consultoria especializada e pela necessidade constatada de se ordenar e desenvolver o turismo no município; também foram utilizadas pesquisas para saber a razão e o significado que as estratégias em elaboração tinham para os atores envolvidos.

\subsection{Diretoria de Esportes e Turismo da Prefeitura Municipal de São Caetano do Sul}

O município de São Caetano do Sul pertence à região do ABC Paulista. Situado a $11 \mathrm{~km} \mathrm{da}$ capital do estado, possui $15 \mathrm{~km}^{2}$ e 151.103 habitantes. É uma cidade de economia forte, baseada especialmente na indústria e comércio, classificada entre os 50 municípios mais ricos do país e entre os 12 melhores para se trabalhar. Além disso, seus habitantes desfrutam da maior renda per capita da região do Grande $\mathrm{ABC}$. O município se destaca ainda em relação à qualidade de vida, sendo a melhor cidade brasileira em termos de Índice de Desenvolvimento 
Humano. O fluxo turístico no município é beneficiado por sua proximidade da capital paulista. Os segmentos mais explorados são o turismo de negócios, o cultural e o de lazer. A cidade conta com vários hotéis, teatros e parques municipais, além de sediar diversos eventos.

No processo de formulação estratégica, as principais estratégias abordadas pelo turismo do município e suas respectivas ações são: (a) mobilização da população local com a intenção de conscientização para o turismo - principal ação nesse sentido é o Projeto Conhecendo $e$ Aprendendo, que possibilita a visitação dos principais pontos turísticos da cidade. Nesse momento, o projeto é feito em parceria com a Diretoria de Educação e envolve todos os interessados em todas as escolas do município; (b) integração com outros departamentos, que está se solidificando através do COMTUR; (c) divulgação do turismo local, por meio da elaboração de um folder com esta finalidade; (d) melhoria no calendário fixo de festejos, com a inserção da Festa das Nações. Outras realizações, que estavam em fase de planejamento para 2007, correspondem à realização de um Fórum Municipal de Turismo para o $2^{\circ}$ semestre de 2007, à atualização e melhoria do inventário turístico, à realização do estudo de demanda e à verificação da estrutura dos atrativos.

Sobre a deliberação e emergência das estratégias, partiu-se da carência detectada no município, no que tange à infraestrutura de lazer, e daí para a questão da atração de visitantes e de eventos para a localidade.

As principais influências recebidas foram relativas à elaboração de algo que não tivesse custo para a prefeitura ou, em caso da existência de algum ônus financeiro, que existisse a possibilidade de cobrir esse ônus por meio de parcerias ou verbas estaduais ou federais; tudo isso com o intuito de se realizarem ações que possibilitassem melhorias e benefícios ao município de um lado e permitissem visibilidade da administração de outro.

A principal dificuldade apresentada foi a falta de verbas, o que direcionou a elaboração de estratégias para o turismo por caminhos que não fossem demandantes de recursos financeiros em demasia.

No que diz respeito à maneira de elaboração das estratégias, relatou-se a realização de reuniões entre os membros do departamento de turismo da prefeitura, daí surgiram alternativas e, por conseguinte, a escolha da mais viável. Com o advento da criação do COMTUR, as determinações saem das reuniões, que transcendem a gestão pública de um 
único órgão de governo municipal, passando à participação de outras partes interessadas no turismo, que compõem a localidade.

\subsection{Secretaria de Desenvolvimento Econômico e Turístico de Rio Grande da Serra}

Localizado na região do Grande ABC Paulista, a $40 \mathrm{~km}$ da capital, o município de Rio Grande da Serra apresenta uma área de $36 \mathrm{~km}^{2}$ e uma população de 41.215 habitantes. Todo o seu território está protegido por leis ambientais, o que torna a cidade propícia ao desenvolvimento do turismo ecológico. Outras atividades econômicas envolvem agricultura familiar, piscicultura, indústrias não poluentes, comércio e serviços.

Em relação às estratégias e ações tomadas pela Secretaria de Desenvolvimento Econômico e Turístico de Rio Grande da Serra, a partir de estudo preliminar, foi realizada uma apresentação para o Conselho de Turismo do Município e alguns membros do trade turístico, das diretrizes iniciais que vão servir de suporte a todas as demais fases do processo de planejamento e das ações locais.

No que concerne à deliberação e emergência de estratégias, observou-se que o plano de ação com conotações estratégicas ainda estava em discussão. Até o momento da pesquisa, o município só dispunha de ideias ou medidas que poderiam ser adotadas; isso ocorreria por meio da participação e atuação, principalmente, do conselho municipal e do trade turístico local; a introdução do turismo nas agendas, discussões e planos se deveu a uma antiga solicitação local: por que não trabalhar o turismo aqui?

No quesito influências na formulação, além dos membros do Conselho Municipal de Turismo e da Secretaria Municipal de Desenvolvimento Econômico e Turismo, tem havido uma boa receptividade em relação à formulação de planos e projetos para o turismo local. Dentre as maiores contribuições estão as que provêm do trade local, dos voluntários e das faculdades de turismo de São Paulo e grande $\mathrm{ABC}$, que têm utilizado a região para seus estudos de trabalho de conclusão de curso.

Talvez em função de estar em um estágio inicial, ainda não foram detectadas quaisquer resistências ou dificuldades no processo de formulação.

Sobre a maneira ou forma de elaboração, foi observada a seguinte seqüência: (a) elaboração do inventário; (b) agregação de outras informações e análises por parte da secretaria 
municipal; (c) elaboração de estudo preliminar entre secretaria e empresa de consultoria; (d) apresentação do estudo preliminar e um esboço das diretrizes aos stakeholders locais; (e) início das discussões para a preparação de um plano de ação.

\subsection{Diretoria de Turismo da Secretaria de Desenvolvimento Econômico de Guarulhos}

Guarulhos é a segunda cidade mais populosa do Estado de São Paulo, com 1.279.202 habitantes e uma área de $318 \mathrm{~km}^{2}$. Pertence à Região Metropolitana de São Paulo, estando situada a $17 \mathrm{~km}$ da capital. A base econômica do município se fundamenta no tripé indústria, comércio e serviços. Em relação ao turismo, a vocação do município está voltada para o turismo de negócios, tendo experimentado um grande crescimento no setor hoteleiro e na área de eventos. Assim, hoje o município dispõe de um Convention \& Visitors Bureau e possui diversos hotéis de padrão internacional. Vale ressaltar ainda que Guarulhos possui o principal e mais movimentado aeroporto do país.

A partir das análises realizadas, as estratégias e ações tomadas pela Diretoria de Turismo da Secretaria de Desenvolvimento Econômico de Guarulhos envolvem as execuções de Oficinas de Nivelamento Técnico, sensibilização, realização de Conferências de Turismo, consolidação do COMTUR e parcerias com as instituições de ensino, as quais por meio de seus Coordenadores e Professores dos Cursos de Turismo participam do Núcleo Docente do COMTUR e colaboram na formatação da política pública do Turismo no Município, tendo dado sua maior contribuição durante a elaboração da $1^{\mathrm{a}}$ Carta de Turismo.

Em relação à deliberação e emergência das estratégias, essas partiram da articulação e relacionamento entre as seguintes entidades: o Departamento de Turismo, o Conselho Municipal de Turismo, o SEBRAE e o Guarulhos Convention \& Visitors Bureau (CVB).

No início, recebeu-se grande influência do PNMT (Programa Nacional de Municipalização do Turismo) e em seguida do PRT (Programa de Regionalização do Turismo), ambos do Ministério do Turismo, que tem como princípios fundamentais a participação, a sustentabilidade, a integração e a descentralização; do Conselho Regional de Turismo - CRT, que tem a finalidade de organizar e promover o desenvolvimento da atividade turística regional, tendo aglutinado os Conselhos Municipais de Turismo na discussão das políticas regionais. Além disso, as entidades estão alinhadas com as diretrizes do Ministério do 
Turismo, Embratur e Federação Brasileira de Conventions Bureaux quanto às políticas públicas e ações integradas de turismo.

A troca de governo foi apontada como maior dificuldade no processo de formulação, pois em decorrência disso, normalmente, ocorrem mudanças do rumo da política do turismo, tanto na esfera municipal, como na estadual e na federal. Destacou-se, também, que, mesmo tendo como tendência relevante a crescente consciência ambiental e o crescimento econômico e turístico do município, é extremamente difícil sensibilizar as autoridades e a comunidade em geral para o desenvolvimento da atividade turística.

Por último, no que se refere à maneira ou forma de elaboração de estratégias, verificou-se que o município partiu da análise dos pontos fortes e fracos do turismo na cidade e da orientação da Carta de Turismo, propondo um foco no turismo de negócios e concomitantemente oferecendo novas formas de se pensar o negócio em turismo, discutindo planos estratégicos de ação, pensando negócio conjuntamente com o destino, e por último, preocupando-se com a regionalização para fins de planejamento, gestão, promoção e comercialização integrada e compartilhada da atividade turística.

\section{Considerações Finais}

A partir da análise dos órgãos municipais de turismo do Estado de São Paulo, no que diz respeito aos casos investigados, foi possível perceber que os procedimentos de análise e formulação estratégica incluem características de formalidade e informalidade e nem sempre são realizados sistematicamente e cotidianamente. Também se verificou, nos municípios, a necessidade de um sistema de informações com perspectivas integradoras, que subsidiassem com maior clareza e rapidez o seu planejamento. Não se confirmou a existência de análises de longo prazo; a maioria parece se limitar a impactos mais de curto prazo sobre os destinos da localidade.

É possível concluir que o conjunto de análises prévias efetuadas revela a preocupação dos municípios estudados em desenvolver um encaminhamento lógico, que consubstancia o processo de formulação de estratégias, na medida em que os órgãos públicos de turismo vão aos ambientes buscar dados, informações e parceiros que contribuam em suas decisões de 
planejamento. Em síntese, as verificações prévias se mostraram úteis, posteriormente, na elaboração e nas decisões das estratégias a seguir.

Sobre as procedências, pode-se afirmar que a iniciativa em relação à formulação partiu dos mais diversos atores, em sua maioria existente no próprio município, que vão desde políticos e gestores públicos, passando pelo trade turístico e até mesmo a população local.

O processo de formulação de estratégias recebe influências de origem tanto interna como externa aos municípios. As práticas encontradas variam desde uma maior participação e democratização do processo, em que os diversos envolvidos possuem amplo acesso à informação e voz para opinar nos assuntos importantes; até decisões impostas de cima para baixo, com participação mais restrita aos governantes locais e aos principais atores do trade turístico local.

A maneira como as estratégias são formuladas abrange desde características de informalidade, por meio de novas ideias, trocas, convencimentos e reuniões; até momentos de maior estruturação, com reuniões envolvendo lideranças e interessados mais representativos do turismo local; contratação de consultorias para acompanhamentos e preparação de métodos; criação de associações de classe para defender interesses de grupos e locais; formação de parcerias; instituição de grupos de trabalho; envolvimento do poder público, dentre outros.

Diante do exposto, acredita-se que a realização deste estudo permitiu ampliar o conhecimento científico e acadêmico sobre a formulação de estratégias em municípios turísticos, contribuindo para a gestão pública de turismo no Estado de São Paulo e oferecendo subsídios para futuros projetos, tanto na área pública, como na área privada.

\section{Referências}

ABRAMO, Perseu. 1979. Pesquisa em ciências sociais. In: HIRANO, Sedi (org.). Pesquisa social: projeto e planejamento. São Paulo: T. A. Queiroz.

ANDREWS, Keneth R. 1987. The Concept of corporate strategy. 3. ed. Homewood, IL: Irwin.

BETHLEM, Agrícola. 2001. Estratégia empresarial. 3. ed. São Paulo: Editora Atlas.

CASTRO, Armando A. 2004. Turismo e carnaval na Bahia. Revista Turismo \& Desenvolvimento, v. 3, p. 63-74, Campinas.

CHANDLER, Alfred D. Jr. 1962. Strategy and structure. Cambridge, MA: M.I.T Press.

CHRISTENSEN, C. Roland; ANDREWS, Kenneth R.; BOWER, Joseph L. 1978. Business Policy. 4. ed. Homewood, IL: Richard D.Irwin. 
CLAVER-CORTÉS, Enrique; MOLINA-AZORÍN, José; PEREIRA-MOLINER, Jorge. 2006. Strategic groups in the hospitality industry: intergroup and intragroup performance differences in Alicante, Spain. Tourism Management, v. 27, p. 1101-16.

COSTA, Benny Kramer. 1999. Análise estratégica na gestão de empresas hoteleiras: proposição de um modelo. Tese (doutorado), FEA USP.

DELAMARO, Maurício C.; TOMASELLA JUNIOR, Sérgio; BRITO, Renato M.; GASPAR, Thiago A. 2007. A dinâmica das políticas públicas do setor de turismo nos municípios do Cone Leste Paulista: reflexões sobre a dimensão político-institucional da sustentabilidade. Caderno Virtual de Turismo, v. 7, n. 1, p. 104-116.

DIXIT, A. K.; NALEBUFF, B. J. 1991. Thinking strategically. New York: W. Norton \& Co.

DRUCKER, Peter F. 1997. An introductory view of management. New York: Harper's College Press.

EMBRATUR. 2007. Estatísticas básicas de turismo. Brasília.

FITZGERALD, Joan; LEIGH, Nancey Green. 2002. Economic revitalization: cases and strategies for city and suburb. Thousand Oaks, Califórnia: Sage Publications Ltd.

FLETCHER, John; COOPER, Chris. 1996. Tourism strategy planning. Annals of Tourism Research, v. 23, n. 1, 181-200.

FORTE, Ana M. S. 2003. A construção do planejamento estratégico de turismo de Juiz de Fora. Caderno Virtual de Turismo, v. 3, n. 3, p. 7-13.

GETZ, Donald. 1983. Capacity to absorb tourism: concepts and implications for strategic planning. Annals of Tourism Research, v. 10, p. 239-63.

HAMEL, Gary; PRAHALAD, C. K. 1995. Competindo pelo futuro. 10. ed. Rio de Janeiro: Editora Campus.

HAX, Arnold C.; MAJLUF, Nicolas S. 1991. The strategy concept and process. Englewood Cliffs, NJ: Prentice-Hall.

LORANGE, P.; VANCIL, R. F. 1977. Strategic planning systems. New Jersey: Prentice-Hall.

LUQUE-MARTÍNEZ, Teodoro et al. 2007. Modeling a city's image: the case of Granada. Cities, v. 24, n. 5, p. 335-52.

MINTZBERG, Henry. 1990. Strategy Formulation: Schools of Thought. In: FREDERICKSON, J. (org.). Perspectives on Strategic Management. Boston: Ballinger.

MINTZBERG, Henry; WATERS, James A. 1985. Of Strategies, Deliberate and Emergent. Strategic Management Journal, v.6, n.3, p.257-272.

MONTGOMERY, Cynthia A.; PORTER, Michael E. 1998. Estratégia: a busca da vantagem competitiva. Rio de Janeiro: Campus.

NEWMAN, William H. 1950. Administrative action. New Jersey: Prentice-Hall.

OMT. 2007. Tourism highlights.

OMT. 2003. Turismo internacional. 2. ed. Porto Alegre: Bookman.

PORTER, Michael E. 1980. Competitive strategy. New York: Free Press.

RITCHIE, Brent W. 2004. Chaos, crises and disasters: a strategic approach to crisis management in the tourism industry. Tourism Management, v. 25, p. 669-83. 
SAMPAIO, Carlos A. C. 2003. Um novo enfoque analítico de processos de tomada de decisão inseridos em metodologias de aplicação de Agendas 21 e do PNMT: uma alternativa para promover o desenvolvimento sustentável. Turismo - Visão e Ação, v. 5, n. 2, p. 169-187, maio-ago.

SCHELLING, T. C. 1960. The Strategy of conflict. New York: Harvard University Press.

SILVA, Jussara M.; COSTENARO, Alessandra. 2004. Planejamento estratégico: um recurso para o desenvolvimento do turismo municipal. Anais do XXVIII Encontro da Associação Nacional de PósGraduação e Pesquisa em Administração. Curitiba: ANPAD.

STOKES, Robyn. 2008. Tourism strategy making: insights to the events tourism domain. Tourism Management, v. 29, p. 252-62.

WERTHER, William B. \& KERR, Jeffrey L. 1995. The shifting sands of competitive advantage. Business Horizons, may-june.

XIANG, Zheng; FORMICA, Sandro. 2007. Mapping environmental change in tourism: a study of the incentive travel industry. Tourism Management, v. 28, p. 1193-1202.

YIN, Robert K. 1994. Case study research: design and methods. 2. ed. v. 5. London: Sage.

ZACCARELLI, Sérgio B. 2000. Estratégia e sucesso nas empresas. São Paulo: Saraiva.

Recebido em: 22/10/2008 ( $1^{\text {a }}$ versão) $11 / 09 / 2009$ ( $2^{\mathrm{a}}$ versão)

Aprovado em: 02/12/2009 